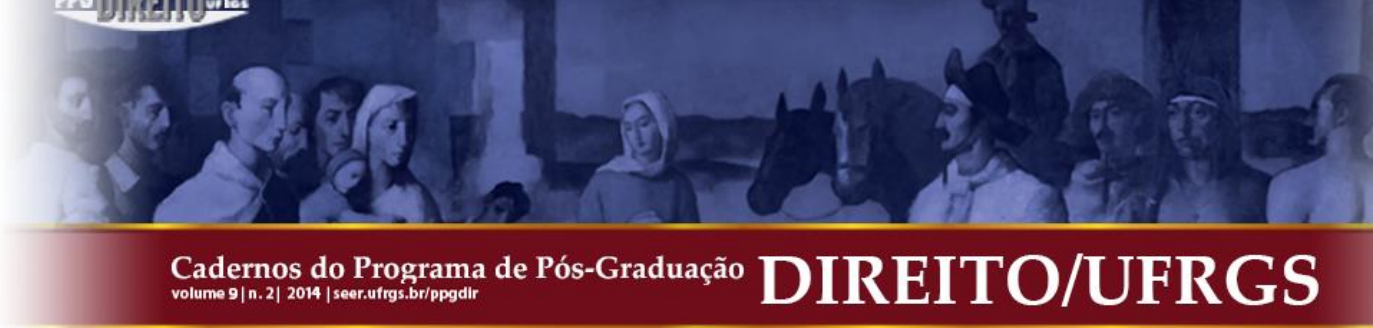

\title{
ENTREVISTA COM MICHAEL STOLLEIS: OS CAMINHOS DA HISTÓRIA DO DIREITO
}

\author{
INTERVIEW WITH MICHAEL STOLLEIS: THE PATHS OF LEGAL HISTORY
}

\section{Gustavo Castagna Machado*}

Michael Stolleis (nascido em 20 julho de 1941 em Ludwigshafen am Rhein) é professor emérito de Direito Público (Öffentliches Recht) e de História do Direito da Modernidade (Neuere Rechtsgeschichte) da Johann Wolfgang Goethe-Universität Frankfurt. Ex-diretor do Max-Planck-Institut für europäische Rechtsgeschichte (1992-2009). Doutor honoris causa pelas universidades de Lund (1999), Toulouse (2002), Pádua (2004) e Helsinque (2010). Membro de diversas academias alemãs (Mainz, Göttingen, BerlinBrandenburg, Halle, Darmstadt), incluindo a Deutsche Akademie der Naturforscher Leopoldina - Nationale Akademie der Wissenschaften (2004), e estrangeiras (Finlândia, Dinamarca), foi agraciado com o Prêmio Leibniz da Deutsche Forschungsgemeinschaft (1991), o Prêmio da Fondazione Eugenio Balzan (2000), com a Bundesverdienstkreuz de $1^{\text {a }}$ Classe (2010) e com a Pour le Mérite für Wissenschaften und Künste (2014).

Ignacio Gutiérrez Gutiérrez recupera em um texto interessantes informações de Stolleis em seu discurso de agradecimento ao receber o Prêmio da Fondazione Eugenio Balzan. Stolleis, nascido na região do Palatinado, atribui às suas origens rurais e às suas ligações com o mundo agrícola (formou-se como viticultor antes de ir para a universidade) uma concepção do trabalho científico como tarefa artesanal e solidária, longe de extravagâncias intelectuais forçadas; foi também aí que se originaram as suas preferências pela tradição narrativa frente a divagação especulativa. Os seus estudos de Direito em Heidelberg e Würzburg transcorreram na sombra da paixão literária, cultivada, por exemplo, nas classes de Erwin Walter Palm, historiador da cultura e da arte que havia recentemente retornado do exílio na América Latina (tendo passado, inclusive, pelo Brasil), que falava a seus estudantes de diversos autores latinos, como Lorca e Alberti, Góngora, Calderon e Lope

\footnotetext{
"Entrevistador e tradutor. Doutorando em Direito pela Universidade Federal do Rio Grande do Sul (UFRGS) com período doutoral (bolsa CAPES/PDSE) no Max-Planck-Institut für europäische Rechtsgeschichte (MPIeR), Frankfurt am Main (proc./CAPES BEX 10549/13-7).
} 


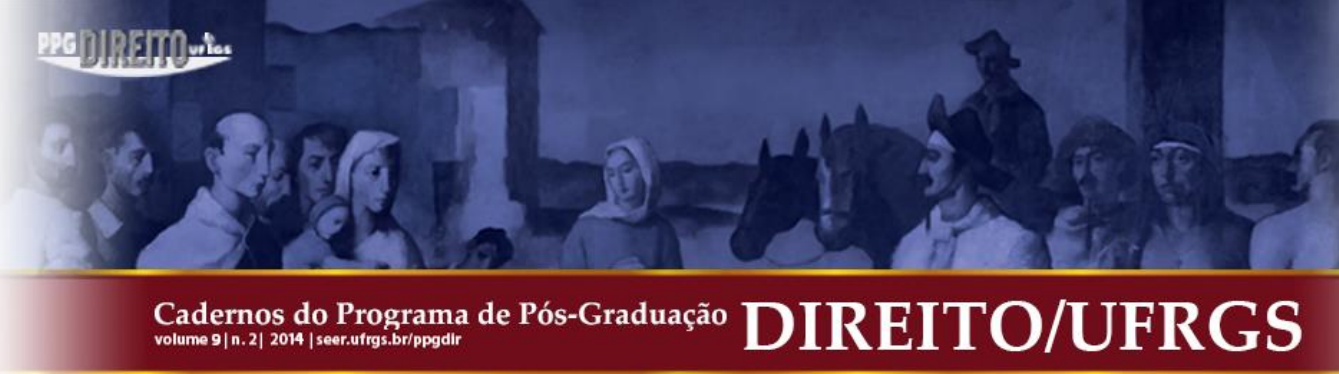

as guerras e os tratados de paz, a organização do Império, tampouco de retornar a uma história das ideias políticas em um desenvolvimento imaginário livre. A História do Direito Público de Stolleis deveria ser uma história de autores e livros, universidades, faculdades, academias e estudantes, conselheiros e diplomatas. Com o intuito de avaliar a disseminação e significado das diferentes posições em cada tempo, também era necessário aprofundar os nomes menos lembrados e vencer a tentação de reconstruir racionalmente os processos de acordo com dados disponíveis apenas a posteriori. Ele teve de mergulhar no contexto adequado dos autores e suas construções, marcado não apenas pela alta política, mas também, por exemplo, especialmente na Alemanha, pelas diferenças religiosas (luteranos, calvinistas, jesuítas etc.). Trata-se, em suma, de analisar em detalhe a institucionalização progressiva do pensar jurídico-público a respeito do poder. ${ }^{3}$

Surge então o primeiro volume de sua magnum opus. O primeiro volume da “Geschichte des öffentlichen Rechts in Deutschland”, finalmente publicado em 1988, abrange desde meados do século XVI até a queda do Império em 1806. No segundo volume, que aparece quatro anos mais tarde, é abordado com a mesma ideia norteadora o longo século XIX, que começa com a Revolução Francesa e termina em 1914: tempos politicamente turbulentos que são extremamente produtivos para o pensamento constitucional. O terceiro volume estende-se do final da primeira Guerra Mundial até a queda do regime nazista, o período de ouro da criação intelectual durante a República de Weimar e seu desenvolvimento doloroso sob o regime de Hitler. ${ }^{4}$

Com isso se encerra, de certa forma, o arco histórico que delimita a tese e o escrito de Habilitation. Porém, isso não esgotou as energias intelectuais de Stolleis, que publicou em 2012 um quarto volume que tratou da história do Direito Público nas duas Alemanhas, de 1945 até a reunificação de 1989/1990. No ano de 2014 sairia um livro que resume os quatro volumes em um único, chamado "Öffentliches Recht in Deutschland. Eine Einführung in seine Geschichte (16.-21. Jahrhundert)”. A projeção para o futuro das lições da história está geralmente fora de suas reivindicações imediatas, mas elabora estudos como "Was kommt nach dem souveränen Nationalstaat? Und was kann die Rechtsgeschichte dazu sagen?” (2004) ou "Vormodernes und postmodernes Recht" (2008). No Direito Público, especializa-se em

\footnotetext{
${ }^{3}$ GUTIÉRREZ, Ignacio Gutiérrez. Presentación. In: STOLLEIS, Michael. La Historia del Derecho como obra de arte. Edición y traducción Ignacio Gutiérrez Gutiérrez. Granada: Comares, 2009, p. VIII.

${ }^{4}$ Ibidem, p. VIII-IX.
} 


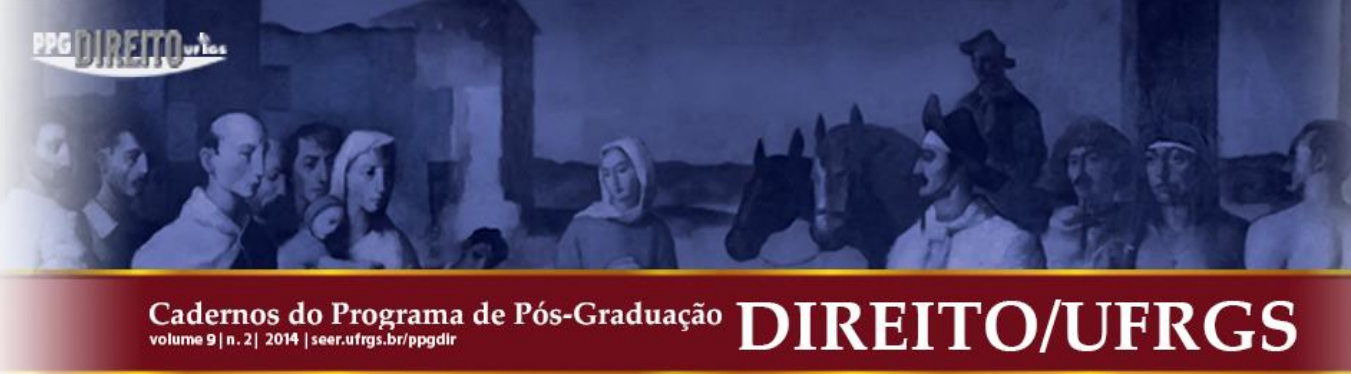

Sozialrecht (proteção e assistência social, a proteção da juventude ou deficientes etc.) do ponto de vista histórico (“Geschichte des Sozialrechts in Deutschland”, 2003) e considerandoo também como um objeto da atual política do Direito. Sua contribuição para a difusão da perspectiva histórica ao considerar os problemas jurídico-públicos tem sido decisiva em especial por uma intensa colaboração no Frankfurter Allgemeine Zeitung ou na revista Mercur. Ignacio Gutiérrez Gutiérrez afirma que seus trabalhos docentes na Universidade e no Max-Planck-Institut e seu compromisso com a organização e promoção de pesquisas e seminários elevaram Frankfurt am Main ao status de capital europeia da História do Direito. ${ }^{5}$ Já Norbert Frei afirma que "Michael Stolleis die Rechtsgeschichte in Deutschland verkörpert" (Michael Stolleis personifica a História do Direito na Alemanha). ${ }^{6}$

Na presente entrevista, concedida em dezembro de 2014, Stolleis fala a respeito de variados temas, tais como sua trajetória acadêmica, a situação atual da disciplina de História do Direito na Alemanha, método, currículo dos cursos jurídicos e o MPIeR, instituto que dirigiu por quase vinte anos. Busca-se, assim, com uma entrevista voltada ao leitor latinoamericano e, mais especificamente, brasileiro, fornecer subsídios para um diálogo intercultural a respeito dos rumos da pesquisa e da área da História do Direito.

Gustavo Castagna Machado (GCM): Você poderia nos contar a respeito do que lhe fez optar pela carreira jurídica?

Michael Stolleis (MS): A minha decisão de estudar Direito não foi por inclinação, mas realmente pragmática - como muitos outros fizeram e fazem. Meu pai estudou Direito e advogou durante minha época de escola. O curso jurídico parecia ser "prático", uma vez que nele existem muitas opções para encontrar o seu próprio caminho. Meus verdadeiros interesses e paixões estavam nos campos da literatura e da história da arte.

GCM: Tendo seguido a carreira jurídica, posteriormente você decidiu pesquisar na área da História do Direito. Por que História do Direito? Essa escolha teve a ver com algum professor que você teve? Tem relação com algum fato marcante de sua vida? Algum livro

\footnotetext{
${ }^{5}$ Ibidem, p. IX.

${ }^{6}$ FREI, Norbert. Nachwort. In: STOLLEIS, Michael. Nahes Unrecht, fernes Recht. Göttingen: Wallstein, 2014 , p. 167.
} 


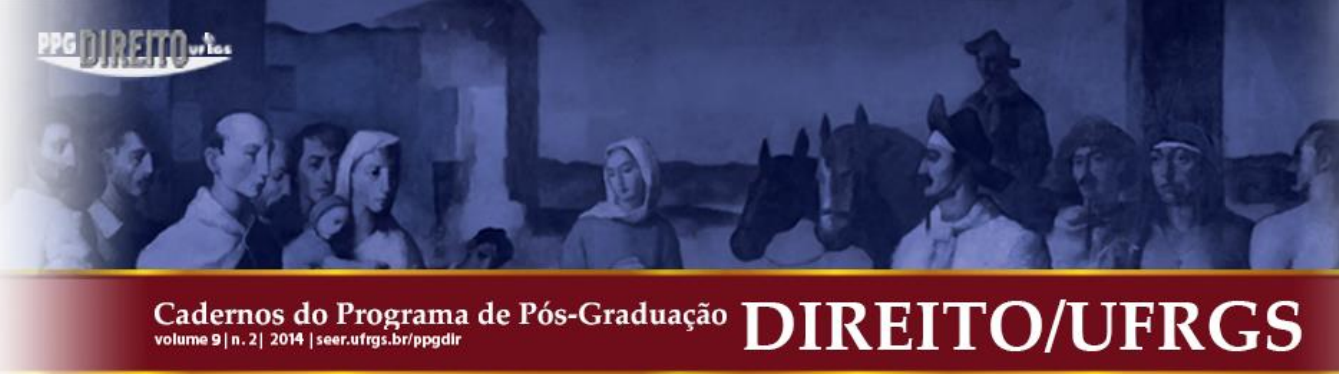

que você leu durante a graduação influenciou de forma especial o caminho que viria a seguir posteriormente como pesquisador?

MS: A primeira vez que eu tive contato com a História do Direito não foi durante meus estudos, mas enquanto eu estava escrevia minha dissertação. Em 1965, eu entrei em contato com os historiadores do Direito Hermann Krause e Sten Gagnér. Gagnér (1921-2000) mudouse da Suécia para Munique no ano anterior. Eu me tornei o seu primeiro doutorando. Todo mundo estava impressionado com seus seminários lendários e eu também fiquei muito impressionado. Eu ainda sou influenciado por seu livro "Studien zur Ideengeschichte der Gesetzgebung” (1960), suas convicções metodológicas e sua personalidade.

GCM: Quais foram os seus grandes mestres [além dos supramencionados]?

MS: Embora eu não fosse um de seus alunos, eu gostaria de adicionar Wolfgang Kunkel grande professor de Direito Romano. Quando eu era um estudante, quase todo mundo já havia lido seu "Römische Rechtsgeschichte" e o admirava por sua erudição. Um segundo jurista, que se tornou muito importante para mim durante o meu tempo em Munique, foi Hans F. Zacher, professor de Direito Público e um expert em Direito Social. Certamente foi ele que me levou ao Direito Social, que eu representaria mais tarde, em Frankfurt. Quando ele se tornou o presidente da Sociedade Max Planck, nos reencontramos e mantemos contato até hoje.

GCM: No seu novo livro "Nahes Unrecht, fernes Recht”, você fala que você possui uma forte opinião, que não é compartilhada por todos os historiadores do Direito: a opinião de que os historiadores do direito são historiadores ("Rechtshistoriker sind Historiker"). Você poderia nos falar um pouco mais sobre isso? Quando e como foi que você percebeu que a escrita da História do Direito também exige os métodos de pesquisa histórica?

MS: Todos os historiadores do Direito trabalham com fontes antigas, às vezes próximos $a$, às vezes com historiadores. É claro que as nossas perguntas como historiadores do Direito são diferentes daquelas que os historiadores têm, mas os nossos métodos de pesquisa são, inevitavelmente, os mesmos. Ambas as disciplinas têm de interpretar textos, tentar decifrar o 


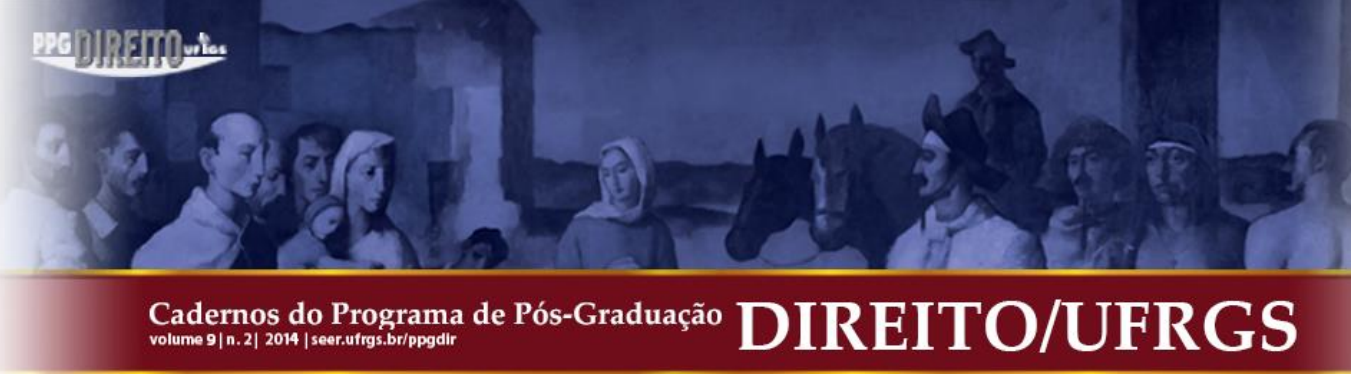

seu significado para compreender e reconstruir o que aconteceu no passado. A única maneira de fazer isso é analisar o texto, isto é, a linguagem.

A História do Direito é necessariamente uma disciplina entre as linhas da pesquisa histórica e das questões jurídicas atuais. Estudar Direito pode ajudar a identificar os elementos jurídicos nas fontes, mas às vezes o "pensamento jurídico" confunde nossa pesquisa. Como juristas, corremos o risco de concluir muito rápido - a partir de nosso ponto de vista contemporâneo, projetar uma maneira de pensar o passado. Apontando para essas questões metodológicas, eu gostaria de mencionar o pequeno livro "La Historia del Derecho como obra de arte" (Editorial Comares, Granada, 2009), traduzido por Ignacio Gutiérrez. Uma versão em português está sendo preparada por Gustavo César Machado Cabral (Universidade Federal do Ceará).

GCM: Falando em método, qual você acredita ter sido a principal marca metodológica de seus escritos? $O$ que você entende ser a sua principal contribuição para a pesquisa em História do Direito, em termos de método?

MS: Em termos de método eu sempre enfatizo a proximidade com os historiadores. Eu nunca fui hostil à teoria, mas eu sempre ressalto que a teoria tem que ser provada pela fonte - não há declaração útil sem exame empírico. Os principiantes muitas vezes pensam que teriam que começar com um monte de teorias, definições e elaborações conceituais. Eu aconselharia a ler o máximo dos originais que puder - pour prendre le ton. Se você faz pesquisa histórica, em primeiro lugar você tem que entender as necessidades, desejos, anseios e as interações das pessoas que você está analisando.

GCM: Você foi durante quase duas décadas diretor do MPIeR (1992-2009), que carrega a fama de ter uma abordagem sofisticada da História do Direito. Embora se entenda que o Instituto tem muitos pesquisadores e nem todos eles pensem da mesma forma, em termos gerais, qual o grande diferencial do Instituto, principalmente durante o seu tempo como diretor?

\footnotetext{
** Aqui Stolleis faz referência, em específico, ao texto traduzido ao espanhol com o título de "Escribir historia del derecho: ¿reconstrucción, narración o ficción?” (original: "Rechtsgeschichte schreiben. Rekonstruktion, Erzählung, Fiktion?”).
} 


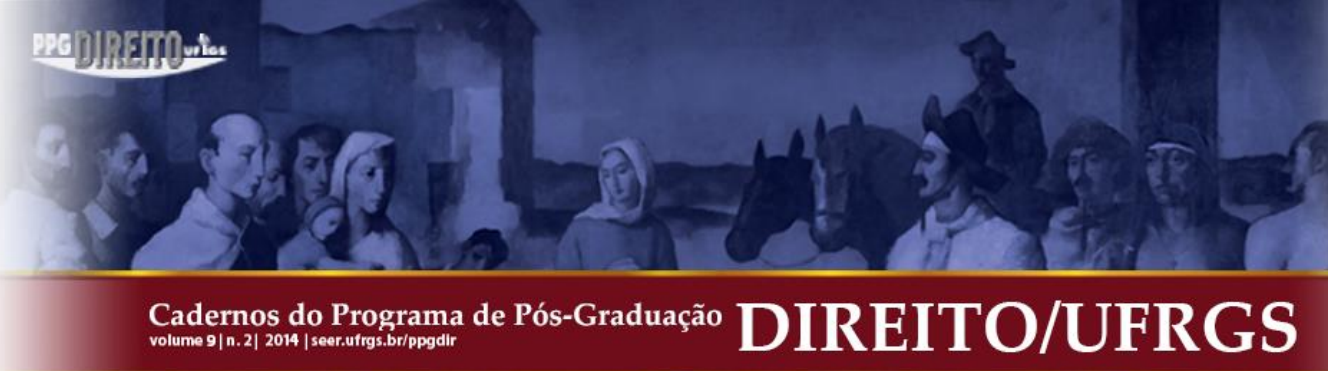

MS: O Instituto Max Planck de História do Direito Europeu é um instituto dentre muitos outros. O MPI tem a vantagem de dispor de uma biblioteca excepcional (que possui mais de 400.000 títulos). Você tem a possibilidade de se focar na pesquisa e apenas em pesquisa - em um ambiente estimulante, porque há pesquisadores excepcionais de todo o mundo.

Mas também é claro que não podemos nos separar das universidades - especialmente da Universidade de Frankfurt. Como pesquisadores, temos a responsabilidade de passar o nosso conhecimento e apoiar os jovens profissionais. Eu sempre tentei estar em contato com os historiadores do Direito da Universidade Goethe e, claro, com os outros colegas da Alemanha e do exterior. E eu estou muito feliz que o meu sucessor, Thomas Duve, continua a fazê-lo.

Quando fui diretor do MPI, tentei fazer avançar a digitalização de nosso catálogo da biblioteca. Dieter Simon, meu predecessor e codiretor, começou esse processo. Isso foi uma prova de força de todos - administração, gestão da biblioteca e Sociedade Max Planck. Eu também fiz andar a construção de um novo edifício para o nosso instituto, que foi concluída em 2013. No que diz respeito à pesquisa, voltar-se ao Direito Público foi muito importante; em específico, eu comecei a escrever uma "História Intelectual" do Direito Público. Nesse contexto, um grande projeto foi a abordagem das "Policeyordungen" (ordens policiais) no início dos tempos modernos (1500-1800). Mais tarde, estabelecemos grupos de trabalho para o estudo da História do Direito internacional, para a história da normalização técnica e para a questão de "Alter und Recht" (Idade e Direito).

GCM: (No Brasil, em um curso que tem cinco anos de duração, normalmente existe apenas uma cadeira de História do Direito. A disciplina de História do Direito, quando consta na grade obrigatória do curso, ainda está, em uma grande parte das universidades, vinculada a departamentos de Direito Privado, sendo pensada como uma escola preparatória para o Direito Privado, nos termos de Wieacker. Às vezes se fala um pouco de Direito Público, para "equilibrar" a disciplina - até mesmo porque hoje muitos brasileiros especialistas em Direito Privado debatem sobre uma assim chamada "constitucionalização do Direito Privado". Esse é o caso, por exemplo, de nossa universidade (UFRGS), e que o faz de um ponto de vista europeu, mas nada ou muito pouco se fala sobre a História do Direito no nosso próprio país, a ponto de a maioria dos graduados em Direito brasileiro concluírem o 


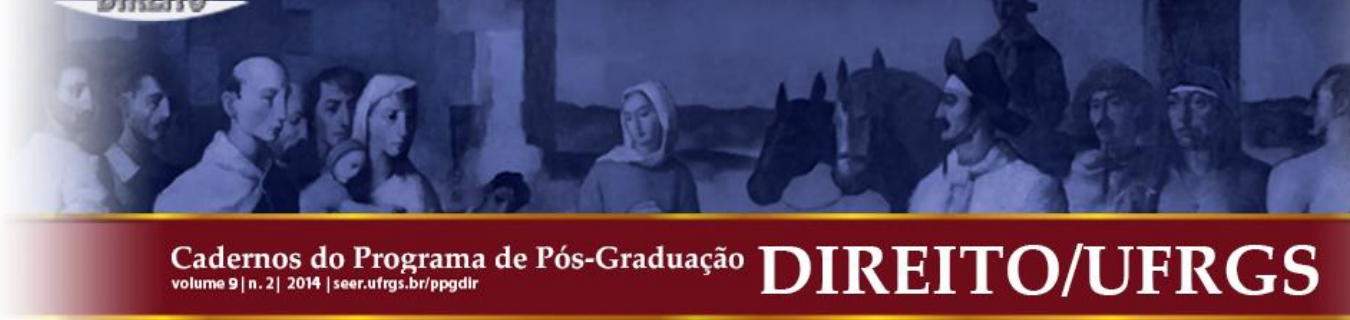

curso ignorando a nossa história jurídica. Mas a impressão de quem olha de fora é que isso não é assim na Alemanha.) Quais foram as mudanças na Alemanha na disciplina da História do Direito na história recente? Qual é a situação geral da disciplina de História do Direito na Alemanha nos cursos de Direito e, mais especificamente, na Universidade de Frankfurt, onde você lecionou durante muitos anos? No caso de Frankfurt, quantas cadeiras obrigatórias de história os principais cursos de Direito costumam ter? Como é feita a divisão por matérias dessas cadeiras? Você chegou a formar opinião a respeito de quantas cadeiras seria o ideal?

MS: É difícil comparar diferentes currículos. Naturalmente cada país tem sua própria cultura jurídica, o que significa que existem diferentes necessidades e expectativas, diferentes concepções do que um jurista deve ser, uma vez que existem diferentes formas de pensar o que o Direito deve realizar. E é claro que isso tem um impacto sobre os currículos. Se um país está à procura de "práticos" (juízes, promotores, notários etc.), não haverá ênfase na História do Direito - em tendência. É claro que essa é uma forma de pensar que não consigo me identificar. A História do Direito não é simplesmente um "refinamento", mas fundamento para a nossa compreensão do Direito em geral. Os fundamentos históricos, filosóficos e metodológicos do Direito devem fazer parte do currículo. O Direito aplicável muda muito rápido, mas seus fundamentos, não.

Mas na Alemanha essas disciplinas básicas - Filosofia e Teoria do Direito, História do Direito - estão em situação precária, também. A globalização e a expansão da União Europeia trouxeram uma ampliação de matérias relevantes (Direito Financeiro, Direito e Economia, Direito da Proteção de Dados, Direito do Trabalho, Direito Previdenciário, Direito Ambiental), mas a duração do estudo permaneceu a mesma. O tempo entre o primeiro e o segundo exame estatal (Staatsexamen) foi ainda reduzido.

A História do Direito permanece "conservadora" nestes tempos. A História do Direito Privado ainda é muito dominante. A proporção de Direito Público, Internacional e Penal na História do Direito é pequena - você pode dizer que são o hobby de alguns professores.

A História do Direito em Frankfurt é uma exceção. Há quatro cátedras; uma de história jurídica antiga (Guido Pfeifer), uma de medieval (Albrecht Cordes), uma do início do período moderno (David von Mayenburg) e, também, uma de história do Direito dos séculos XIX e XX (Louis Pahlow). E nós devemos acrescentar os diretores do MPI (Duve, 


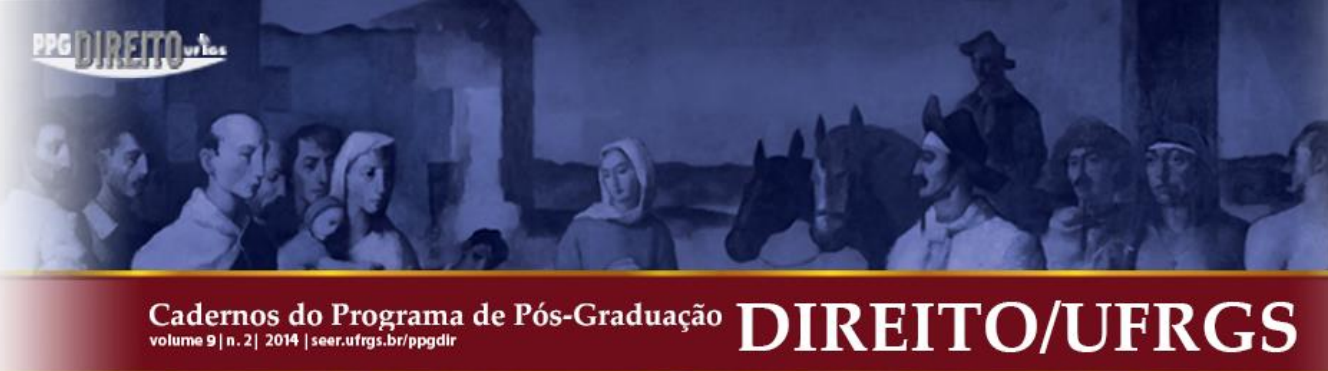

Vogenauer), bem como o eméritos que ainda estão praticando (Diestelkamp, Dilcher, Rückert, Stolleis). Existiu uma escola de pós-graduação conjunta como uma forma de interação entre o MPI e a Universidade. E há uma escola de verão a cada ano no MPI e, claro, diversas palestras e conferências. De fato, somos uma numerosa equipe.

GCM: Em 1996 você publicou um artigo no Frankfurter Allgemeine Zeitung chamado “Der geschichtsblinde Jurist ist gefährlich" ("O jurista cego à história é perigoso"). Passados quase 20 anos, você ainda mantém a mesma opinião? Como você entende a História do Direito e qual a principal função da disciplina de História do Direito no currículo de uma graduação? Qual a relevância de uma disciplina de História do Direito concebida nos seus termos na grade curricular de um curso de Direito?

MS: Nada mudou no que se refere a essa declaração. Eu ainda estou convencido de que informar os alunos a respeito da História do Direito é uma necessidade para manter uma cultura de Direito democrático e liberal vivo. É a melhor forma de transmitir os nossos valores. Diante de nossa História, temos uma responsabilidade especial de fazer isso. A esse respeito, eu pleitearia que uma História do Direito contemporâneo tivesse considerada a sua inclusão no currículo. Não é para tentar moralizar, mas para buscar motivos, por que e como as ordens normativas tornaram-se questionáveis e instáveis - e como isso leva à violência e à guerra.

GCM: Em 2012, foi lançado o quarto e último volume da sua História do Direito público alemão, que lida com a época da divisão alemã. Nele você repetidamente se refere à inseparabilidade entre Direito Público e eventos políticos. Você poderia nos falar um pouco mais sobre isso? Como você caracteriza essa estreita relação entre Direito e Política no trabalho de um historiador? Quando se faz História do Direito Público, em que medida é importante o pesquisador dominar a História politica e social e, também, o pensamento politico do país que é objeto de sua pesquisa?

MS: O Direito Público, em especial o Direito Constitucional, é inevitávelmente ligado à política. O Direito Público é em si mesmo um assunto "político". Naturalmente, todos os estudos jurídicos são de alguma forma políticos, mas no Direito Público é óbvio. E, devido a 


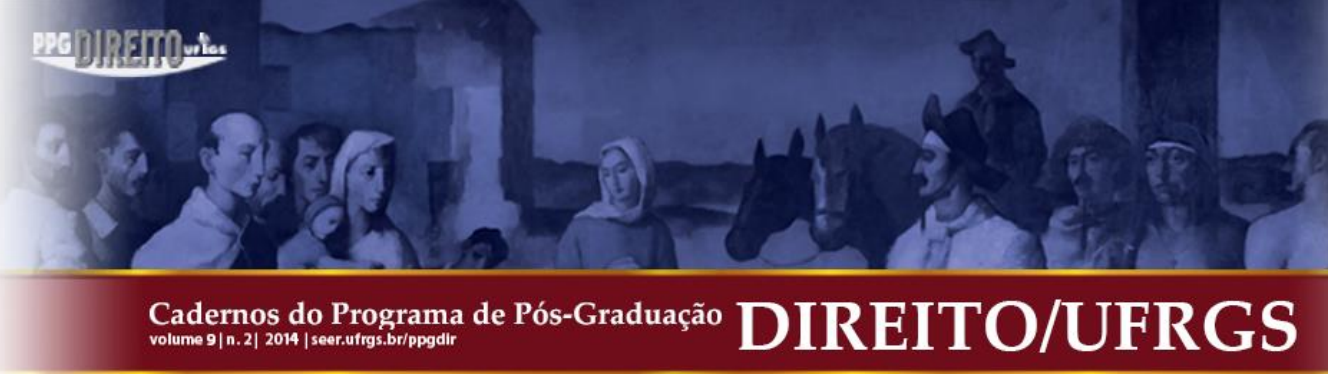

Em 2013, o Wissenschaftsrat [Conselho Científico], uma organização independente, mas oficial, insistiu em um relatório especial que fossem revalorizadas as disciplinas fundamentais, caso contrário os cursos jurídicos na Alemanha se tornariam menos atraentes para o mundo acadêmico internacional (ver a discussão e minha posição a respeito disso em: Juristenzeitung 2013, pp. 693-714).

GCM: Recentemente, há uma multiplicação de traduções para o português e espanhol de livros dogmáticos do Direito alemão, principalmente na área do Direito Público. Como historiador do Direito, como você vê isso, considerando que, embora por um lado se possa ter acesso a clássicos e estabelecer diálogos, simultaneamente, o público leitor (eu estou pensando na América Latina) pouco ou nada conhece sobre tais autores e o contexto jurídico e político em que tais obras foram produzidas (o que, e.g., leva a já clássicas trapalhadas e confusões em relação aos papeis de $H$. Kelsen e C. Schmidt durante o período nacional-socialista alemão)?

MS: O que você chama de multiplicação é de fato uma tendência gratificante, especialmente olhando para as línguas espanhola e portuguesa. Claus Roxin tornou-se com o seu excelente manual de Direito penal muito importante para a América do Sul. E o mesmo acontece com Peter Häberle no Direito Público, que eu conheço como uma pessoa liberal e diferenciada. Na mesma medida, a tradução de publicações no campo da História do Direito aumenta. E com isso as velhas narrativas (Kelsen, Schmitt) estão desaparecendo, o que abre a possibilidade a um pensamento diferenciado.

Eu sempre advogo mais traduções - fora da língua habitual, que costuma ser o inglês (recentemente escrevi sobre isso em um artigo no Frankfurter Allgemeine Zeitung, de $1^{\circ}$ de outubro). Não devemos ser dependentes do mercado anglo-americano, mas entrar em diálogo.

GCM: Em que medida o que se discute a respeito da História do Direito vale também para o Direito Comparado? Pergunto isso, pois, no Brasil, temos visto a multiplicação de muitos trabalhos de Direito comparado, mas que olvidam contextualizações históricas, de tipo politico, econômico, social etc., ficando muitas vezes em uma comparação superficial de normas e doutrinas jurídicas, algumas vezes colorida por citações de decisões judiciais sem muito contexto. 


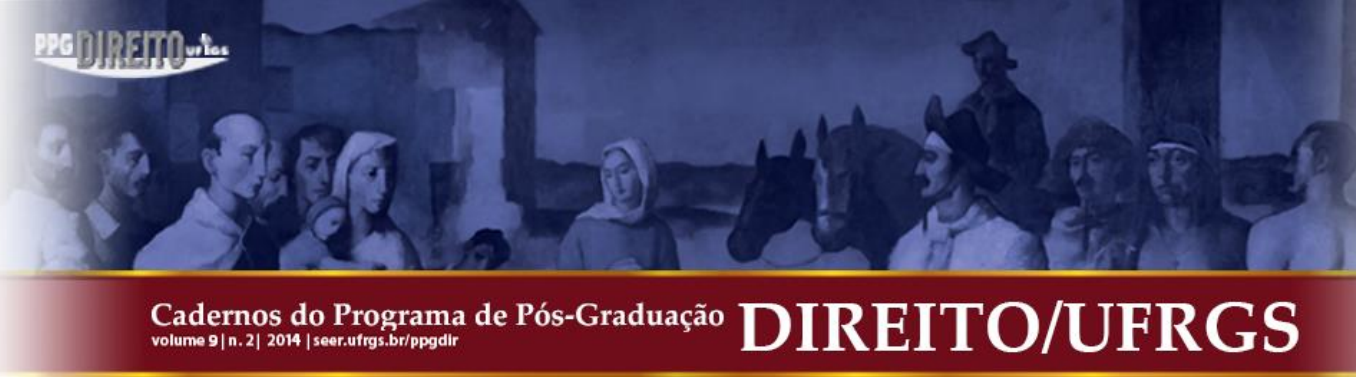

MS: O que foi dito a respeito da História do Direito é aplicável ao Direito Comparado, também. Uma comparação superficial de diferentes normas, sem ter um olhar para o contexto social e histórico é quase inútil, pode-se dizer. É simplesmente impossível compreender a diferença ou conformidade de normas, se você não observar o contexto em que foram produzidas e em que estão a produzir efeito. As normas podem ser superficialmente iguais - o decisivo é o que elas afetam.

GCM: Quais livros você considera os seus principais, tem mais orgulho de ter escrito, e por quê?

MS: Eu confesso estar um pouco encabulado com essa questão. Retrospectivamente, há muito em meus livros que poderia ter sido feito melhor. Mas todo livro que você escreve significa uma nova experiência, um novo conhecimento e talvez um passo adiante na compreensão da História do Direito. E é claro que eu tenho que mencionar aqui o meu "Geschichte des öffentlichen Rechts" (4 vols.: 1988, 1992, 1999, 2012), ${ }^{* * *}$ que foi muito traduzido. Foi uma tarefa muito desgastante, mas bem recebida.

GCM: Para concluir: hoje você é um dos juristas mais premiados da História da Alemanha, tendo realizado pesquisas e escrito a respeito de temas que, na época em que você os fez, não eram mainstream, eram incomuns, ainda mais na academia jurídica, e ainda poderiam lhe causar problemas, como quando você enfrentou a questão do Direito e nazismo na Alemanha, ou ainda quando em livros como o seu "Geschichte des öffentlichen Rechts in Deutschland" contextualizou determinados autores e doutrinas jurídicas. Como você vê, do ponto de vista da construção de uma carreira de pesquisador, essa questão de escapar de lugares comuns, de ser um precursor e não um continuador, de ler profundamente e conhecer determinado tema até perceber lacunas na produção científica e, mais precisamente, persistir e não abandonar determinadas linhas de pesquisa quando se está convicto. Que conselhos você poderia dar a pesquisadores que se deparam com os

\footnotetext{
*** Uma versão que resume os quatro volumes em um único, chamada "Öffentliches Recht in Deutschland. Eine Einführung in seine Geschichte (16.-21. Jahrhundert)", está sendo traduzida ao português por Gercelia Batista de Oliveira Mendes, com revisão de Ricardo Resende Campos, e será lançada em parceria entre o IDP e a editora Saraiva.
} 


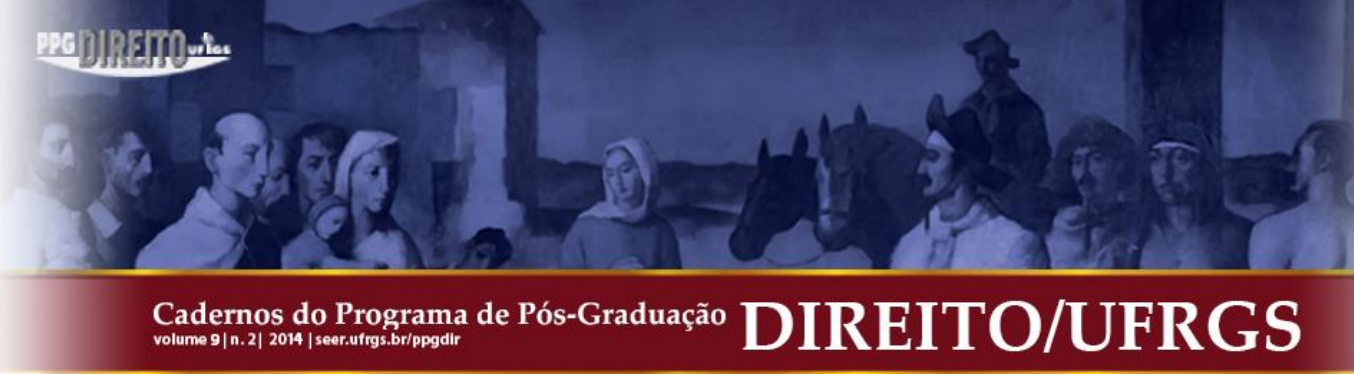

mesmos problemas que você encontrou no começo de sua carreira? Ou ainda, como você os solucionou?

MS: Essa também é uma pergunta difícil. Tudo o que posso dizer: se você escrever um livro, lembre-se de seus próprios estudos e daquilo que uma vez você sentiu falta. Então, dará certo. Mas, em geral: não escreva por motivos errados, tais como dinheiro ou apenas para avançar na carreira. Selecione os temas que lhe interessam e trabalhe neles apaixonadamente!

\section{BIBLIOGRAFIA SELECIONADA DE MICHAEL STOLLEIS}

\section{A Monografias}

Staatsraison, Recht und Moral in philosophischen Texten des späten 18. Jahrhunderts. Meisenheim: Anton Hain, 1972.

Gemeinwohlformeln im nationalsozialistischen Recht. Berlin: J. Schweitzer, 1974.

Pecunia Nervus Rerum. Zur Staatsfinanzierung in der frühen Neuzeit. Frankfurt am Main: Klostermann, 1983.

Geschichte des öffentlichen Rechts in Deutschland. Bd. I, 1600-1800. München: C. H. Beck, 1988 (traduzido ao italiano e ao francês); Bd. 2, 1800-1914, München: C. H. Beck, 1992 (traduzido ao italiano, inglês, francês e chinês), Bd. 3, 1914-1945, München: C. H. Beck, 1999 (traduzido ao inglês e ao chinês), Bd. 4, 1945-1990, München: C. H. Beck, 2012.

Geschichte des Sozialrechts in Deutschland. Stuttgart: Lucius \& Lucius, 2003 (traduzido ao inglês em 2014).

Das Auge des Gesetzes. Geschichte einer Metapher. 2. Aufl. München: C. H. Beck, 2004 (traduzido ao inglês, francês, italiano, espanhol, estoniano, russo, chinês, português).

Sozialistische Gesetzlichkeit. Staats- und Verwaltungsrechtswissenschaft in der DDR. München: C. H. Beck, 2009.

Öffentliches Recht in Deutschland. Eine Einführung in seine Geschichte, 16.-21. Jahrhundert. München: Beck’sche Reihe, 2014. 


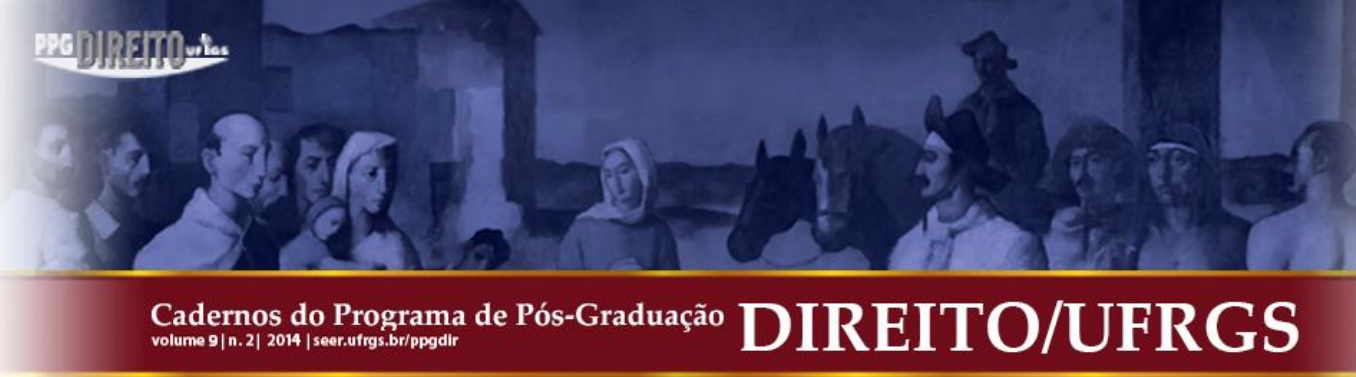

\section{B Obras organizadas (selecionadas)}

Staatsdenker in der frühen Neuzeit. Frankfurt am Main: A. Metzner, 1977 (erw. Aufl. München: C. H. Beck, 1995; traduzido ao japonês em 1995).

Hermann Conring (1606-1681). Beiträge zu Leben und Werk. Berlin: Duncker \& Humblot, 1983.

(com Hans Meyer) Hessisches Staats- und Verwaltungsrecht. Frankfurt am Main: A. Metzner, 1983. (5. Aufl. 2000).

(com Bernhard Diestelkamp) Justizalltag im Dritten Reich. Frankfurt am Main: Fischer TB, 1988.

(com Bernhard Diestelkarnp) Juristen an der Universität Frankfurt am Main. Baden-Baden: Nomos, 1989.

Policey im Europa der frühen Neuzeit. Frankfurt am Main: Klostermann, 1996.

(com Norbert Frei e Dirk van Laak) Geschichte vor Gericht. Historiker, Richter und die

Suche nach Gerechtigkeit. München: C. H. Beck, 2000.

Juristen. Biographisches Lexikon von der Antike bis zur Gegenwart. München: C. H. Beck, 1995. 2. erw. Aufl. München: C. H. Beck, 2001.

(com Adrienne Heritier e Fritz Scharpf) European and International Regulation after the Nation State. Baden-Baden: Nomos, 2004.

(com Lorraine Daston) Natural Law and Laws of Nature in Early Modern Europe. Farnharn: Ahsgate, 2008.

(com Johannes Fried) Wissenskulturen. Über die Erzeugung und Weitergabe von Wissen. Frankfurt am Main: Campus, 2009.

(com Yasutomo Morigiwa e Jean-Louis Halperin) Interpretation of Law in the Age of Enlightenment. Dordrecht et al.: Springer, 2011.

Herzkammern der Republik. Die Deutschen und das Bundesverfassungsgericht. München: C. H. Beck, 2011.

\section{Ensaios (Selecionados)}

Staat und Staatsräson in der frühen Neuzeit. Studien zur Geschichte des öffentlichen Rechts. Frankfurt am Main: Suhrkamp, 1990 (traduzido ao italiano em 1998). 


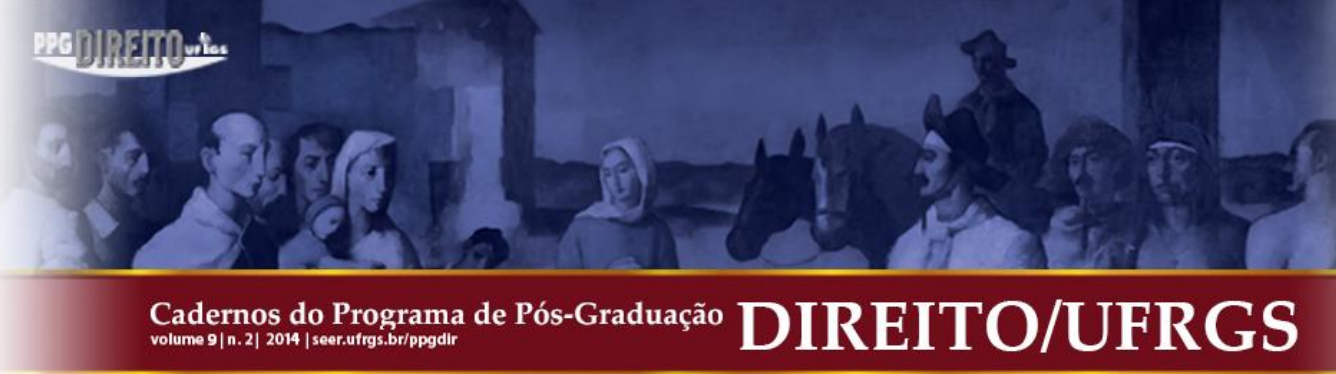

Recht im Unrecht. Studien zur Rechtsgeschichte des Nationalsozialismus. Frankfurt am Main: Suhrkamp, 1994; 2. Aufl. 2005 mit einem neuen Nachwort (traduzido ao inglês em 1998 e ao francês em 2014).

Konstitution und Intervention. Studien zur Geschichte des öffentlichen Rechts im 19. Jahrhundert. Frankfurt am Main: Suhrkamp, 2001.

Ausgewählte Aufsätze und Beiträge. Hrsg. v. Stefan Ruppert und Miloš Vec. 2 Bde. Frankfurt am Main: Klostermann, 2011.

La Textura Histórica De Las Formas Politicas. Madrid: Marcial Pons, 2011.

\section{Traduções (selecionadas)}

\section{Traduções ao espanhol}

Reforma y Derecho público en Alemania. In: KONIECKI, Dieter; ALMARZA-MEÑICA, Juan Manuel (Coords.). Martín Lutero (1483-1983). Jornadas hispano-alemanas sobre la personalidad y la obra de Martín Lutero en el V Centenario de su nacimiento. Madrid: Fundación Friedrich Ebert, 1984, pp. 121 ss.

Las líneas de desarrollo de la dogmática en el Derecho Administrativo en la era industrial. Documentación Administrativa, n. 234, pp. 3-18, abril-junio 1993.

La Historia del Derecho como obra de arte. Edición y traducción Ignacio Gutiérrez Gutiérrez. Granada: Comares, 2009.

Europa como Comunidad de Derecho. Traducción de Ignacio Gutiérrez Gutiérrez. Historia Constitucional: Revista Electrónica de Historia Constitucional, a. 2009, n. 10, pp. 475-484, 2009. Disponível em: < www.historiaconstitucional.com >.

El ojo de la ley. Historia de una metáfora. Madrid: Marcial Pons, 2010.

La textura histórica de las formas políticas. Madrid: Marcial Pons, 2011.

La ínsula Barataria (unas anotaciones sobre utopías, literatura y “policía”). e-Legal History Review, a. 2011, n. 12, 2011.

El Reich como Mito y Metáfora. e-Legal History Review, a. 2011, n. 12, 2011.

(com Andreas Paulus e Ignacio Gutiérrez Gutiérrez). El Derecho constitucional de la Globalización. Madrid: Fundación Coloquio Jurídico Europeo, 2013. 


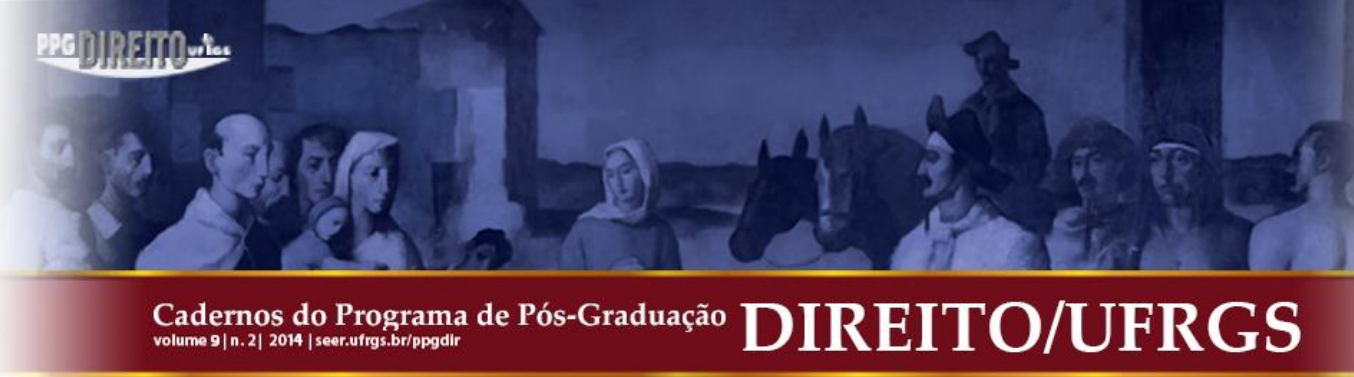

$158,2009$.

Histoire du droit européenne, toujours à l'état de projet?Clio@Themis, n. 1,15 p., 2009.

Comprendere l'incomprensibile: l'olocausto e la storia del diritto. Pólemos. Rivista semestrale di diritto, politca e cultura, n. 1, pp. 193-206, 2010.

Histoire du droit public. v. 2 (1800-1914). Présenté par Jean-Louis Mestre. Paris: Dalloz, 2014.

Le droit à l'ombre de la croix gammée. Traduction Christian Roques. Études sur l'histoire du droit du national-socialisme. No Prelo.

Publicações em e traduções ao inglês

European Legal History - Traditions and Visions. In: MODÉER, K. Å. (Ed.). Rättshistoria $i$ förändring: Olinska stiftelsen 50 år: ett internationellt symposium i Stockholm den 19-21 november 1997. Stockholm: Rönnell Antikvariat, 1997, pp. 167-179.

The Influence of the "Ius Commune" in Germany in the Early Modern Period on the Rise of the Modern State. Rivista Internazionale di Diritto Comune, v. 11, pp. 275-285, 2000.

Reluctance to Glance in the Mirror: The Changing Face of German Jurisprudence after 1933 and post- 1945. Chicago: University of Chicago, 2002. Também em: In: JOERGES, Christian; GHALEIGH, Navraj Singh (Eds.). Darker Legacies of Law in Europe. The Shadow of National Socialism and Fascism over Europe and its Legal Traditions. Oxford and Portland, Oregon: Hart Publishing, 2003, pp. 1-18.

The role of the humanities in western industrialized societies. In: RÜEGG, Walter (Ed.). Meeting the Challenges of the Future. A discussion between "the two cultures". Balzan Symposium 2002 organized by the International Balzan Foundation at the Royal Society, London 13-14 May 2002. Firenze: Leo S. Olschki Editore, 2003. também em: TRAMES Journal of the Humanities and Social Sciences, v. 6, n. 3, pp. 211-217, 2002.

Judicial Review, Administrative Review, and Constitutional Review in the Weimar Republic. Ratio Juris, v. 16, n. 2, pp. 266-280, June 2003.

The dissolution of the Union between Norway and Sweden within the context of international law - hundred years later. In: MESTAD, Ola; MICHALSEN, Dag (red.) Rett, Nasjon, Union. 


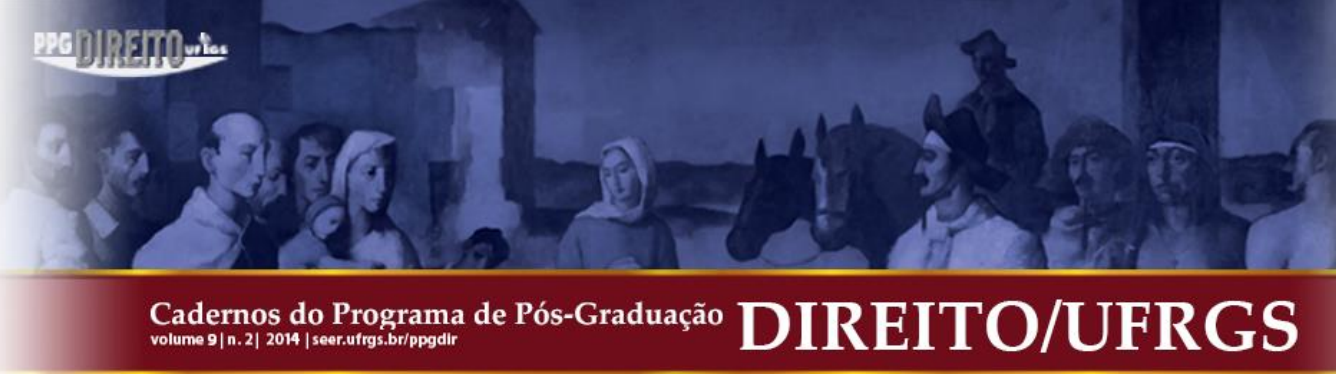

Storia del diritto. L'esperienza tedesca. In: Paolo Grossi (ed.). L'Insegnamento della Storia del diritto medievale e moderno. Firenze: Giuffrè, 1993, pp. 331-338.

Autogoverno: una indagine semantica. In: GOZZI, Gustavo; GHERARDI, Raffaella (ed.). Saperi della borghesia e storia dei concetti fra Otto e Novecento. Bologna: il Mulino, 1995, pp. 249-262.

Sulla storia della giuspubblicistica: ovvero dodici anni di lavoro alla scrivania. Le Carte e la Storia, v. 2, pp. 5-9, 1999.

L'Occhio della legge. Cura di Alessandro Somma. Roma: Carocci, 2007.

Storia del Diritto Pubblico in Germania. Pubblicistica dell' Impero e Scienza di Polizia 16001800. Milano: Giuffré, 2008.

Nel ventre del Leviatano. La Scienza del diritto costituzionale sotto il Nazional-Socialismo. In: MELIS, Guido (ed.). Lo Stato negli anni Trenta. Istituzioni e regimi fascisti in Europa. Bologna: Il Mulino, 2008, pp. 9-34.

La polizia nella prima età moderna. In: BLANCO, Luigi (ed.). Dottrine e istituzioni in Occidente. Bologna: Il Mulino, 2011, pp. 35-56.

Storia del diritto pubblico in Germania. v. 2 (1800-1914). Milano: Giuffrè, 2014.

\section{Traduções ao português}

O Perfil do juiz na Tradição Europeia. Tradução de Isabel Graes. In: Barbas Homem, A. P.; Vera-Cruz Pinto, E.; Costa e Silva, P.; Videira, S.; Freitas, P. (ed). O Perfil do Juiz na Tradição Ocidental. Lisboa: Almedina, 2009, pp. 21-34.

Interpretação Judicial na Transição do Antigo Regime ao Constitucionalismo. Tradução de Gustavo Castagna Machado. Revista Cadernos do Programa de Pós-Graduação em Direito/UFRGS, v. 9, n. 2, 20 p., 2014.

O Olho da Lei. Tradução de Thiago Saddi Tannous. Curitiba: Doyen, 2014. 